\title{
STUDI KOMPARATIF USAHA PERKEBUNAN KOPI ROBUSTA DAN KOPI ARABIKA DI KECAMATAN PANTI KABUPATEN JEMBER
}

\author{
COMPARATIVE STUDY OF ROBUSTA COFFEE AND ARABICA COFFEE CONSTRUCTION IN \\ SUB-DISTRICT OF PANTI, DISTRICT OF JEMBER \\ Wisnu Abimanyu ${ }^{1}$, Syamsul Hadi' ${ }^{2}$, dan Atok Ainur Ridho ${ }^{2)}$ \\ 1) Mahasiswa Program Studi Agribisnis, Fakultas Pertanian, UM Jember \\ 2) Dosen Program Studi Agribisnis, Fakultas Pertanian, UM Jember \\ e-mail : wisnuabimanyu1927@ gmail.com
}

\begin{abstract}
ABSTRAK
Penelitian ini bertujuan (1) untuk mengetahui perbedaan produktivitas lahan dan keuntungan perkebunan kopi robusta dan arabika di Kabupaten Panti Kabupaten Jember. (2) untuk mengetahui efisiensi biaya usaha perkebunan kopi robusta dan arabika di Kecamatan Panti Kabupaten Jember (3) untuk mengidentifikasi faktor-faktor yang mempengaruhi produksi kopi robusta dan kopi arabika di Kecamatan Panti Kabupaten Jember. Penelitian ini dilakukan dengan menggunakan metode deskriptif dan komparatif. Metode pengambilan sampel yang digunakan adalah Dispropotional Random Sampling. Peneliti menggunakan wawancara dan catatan untuk mengumpulkan data. Analisis data yang digunakan dalam penelitian ini adalah (1) rumus produktivitas (2) analisis profit dan efisiensi biaya (3) regresi linier berganda. Hasil analisis menunjukkan bahwa (1) Perbedaan luas produktivitas kopi robusta dan arabika sebesar $1.330 \mathrm{~kg}$ / ha untuk robusta dan $1.150 \mathrm{~kg} /$ ha untuk kopi arabika (2) perbedaan laba bisnis robusta dan arabika menunjukkan bahwa keuntungan Rata-rata Robusta adalah Rp 13.276.003 / ha dan Rp 15.282.105 / ha untuk kopi arabika (3) untuk perbedaan efisiensi biaya robusta adalah 1,86 dan 1,89 untuk kopi arabika. Faktor-faktor yang berpengaruh nyata terhadap produktivitas robusta dan arabika adalah luas lahan (X4), dan varietas tiruan (D1). Sedangkan faktor-faktor yang tidak berpengaruh signifikan terhadap produksi adalah pupuk anorganik (X1), pupuk organik (X2), populasi (X3), tenaga kerja (X5), dan pengalaman (X6)
\end{abstract}

Kata kunci: usaha perkebunan kopi, produktivitas, keuntungan, efisiensi biaya

\section{Abstract}

This research was intended (1) to know the differences of land productivity and the profit of robusta and arabica coffee plantation in Panti district of Jember Regency. (2) to know the cost efficiency of robusta and arabica coffee plantation business at Panti subdistrict of Jember regency (3) to identify the factors that affect the production of robusta and arabica coffee in Panti subdistrict of Jember regency. This research was done by using descriptive and comparative method. The sampling method that was used was Dispropotional Random Sampling.The researcher used interview and note to collect the data. The data analysis that was used in this research were (1) productivity formula (2) profit and cost efficiency analysis (3) multiple linear regression. The analysis result showed that (1) The difference of the productivity area of robusta and arabica coffee that was $1.330 \mathrm{~kg} / \mathrm{ha}$ for robusta and $1.150 \mathrm{~kg} / \mathrm{ha}$ for arabica coffee (2) the difference of robusta and arabica business profit showed that the profit average of Robusta was $R p$ 13.276.003/ha and $R p$ 15.282.105/ha for arabica coffee (3) for the difference of cost efficiency of robusta was 1,86 and 1,89 for arabica coffee. The factors that significantly affected the productivity of robusta and arabica were land area (X4), and dummy varieties (D1). Whereas the factors that had no significant effet on the production were inorganic fertilizer (X1), organic fertilizer (X2), population (X3), labor (X5), and experience (X6)

Keywords: coffee plantation business, productivity, profit, cost efficiency 


\section{PENDAHULUAN}

Salah satu tanaman keras perkebunan adalah tanaman kopi. Kopi adalah suatu jenis tanaman tropis yang dapat tumbuh dimana saja, terkecuali pada tempat-tempat yang terlalu tinggi dengan temperatur yang sangat tinggi atau daerah-daerah tandus yang memang tidak cocok bagi kehidupan tanaman. Sudah beberapa abad lamanya tanaman kopi menjadi bahan perdagangan karena kopi dapat diolah menjadi minuman yang lezat rasanya. Dengan kata lain kopi adalah sebagai penyegar badan dan pikiran. Badan yang lemah dan rasa kantuk dapat hilang setelah minum kopi panas, terlebih orang yang sudah menjadi pencandu kopi, bila tidak minum kopi rasanya akan capai dan tidak dapat berpikir dengan baik (AAK, 1988 dalam Simaibang, 2008). Di dunia perdagangan dikenal beberapa golongan kopi, tetapi yang paling sering dibudidayakan hanya kopi arabika, robusta dan liberika. Pada umumnya penggolongan kopi berdasarkan spesies, kecuali kopi robusta.

Terdapat dua varietas tanaman kopi yang dikembangkan di Indonesia, yaitu kopi arabika dan kopi robusta. kopi arabika merupakan jenis kopi tradisional, dianggap paling enak rasanya, dan kopi robusta yang memiliki kafein lebih tinggi, dapat dikembangkan dalam lingkungan dimana kopi arabika tidak dapat tumbuh, dengan rasa yang pahit dan asam (Anonim, 2009). Selama lima tahun terakhir, Indonesia menempati posisi keempat sebagai negara eksportir kopi setelah Brazil, Kolombia dan Vietnam. Indonesia juga merupakan negara penghasil kopi robusta terbesar kedua di dunia setelah Vietnam (ICO, 2010). Di sisi lain meskipun kontribusi kopi arabika Indonesia dalam perdagangan kopi dunia secara kuantitatif sangat kecil, namun secara kualitatif sangat disukai konsumen dengan keanekaragaman jenis serta cita rasanya yang spesifik.

Kecamatan Panti adalah satu dari 31 kecamatan yang berada di Kabupaten Jember dengan luasan wilayah mencapai 160.71 $\mathrm{km}^{2}$ atau $4.88 \%$ dari luas wilayah keseluruhan Kabupaten Jember. Dengan ketinggian rata-rata 50-1.340 mdpl. Mengingat Kecamatan Panti yang mempunyai kontur tanah yang beragam sehingga memungkinkan untuk dibudidayakan berbagai macam tanaman termasuk tanaman perkebunan. Statistik di kecamatan Panti menunjukan bahwa sebagian besar penduduk berprofesi sebagai petani. Tanaman perkebunan yang biasa yang dibudidayakan di Kecamatan Panti adalah kopi. Mengingat Kecamatan Panti merupakan penghasil kopi terbesar kedua di Kabupaten Jember dibawah Kecamatan Silo. Terdapat dua varietas kopi yang dibudidayakan yaitu kopi robusta dan kopi arabika. Penelitian ini bertujuan untuk mengetahui perbandingan produktivitas lahan dan keuntungan usaha perkebunan kopi robusta dan kopi arabika, efisiensi biaya usaha perkebunan kopi robusta dan kopi arabika, dan faktor-faktor produksi yang berpengaruh terhadap produksi usaha perkebunan kopi robusta dan kopi arabika.

\section{TINJAUAN PUSTAKA}

Teori-teori yang digunakan dalam penelitian ini adalah : (1) Teori Usahatani (2) Teori Produksi (3) Fungsi Produksi CobbDouglas (4) Teori Efisiensi Biaya (5) Teori Biaya (6) Teori Keuntungan (7) Teori Regresi. Terdapat beberapa Penelitian Terdahulu yang digunakan sebagai dasar dalam penelitian ini diantaranya :

1. Thamrin (2014) menyatakan factor factor yang menentukan usahatani kopi arabika di Kabupaten Enrekang adalah variabel biaya usahatani yang dikumpulkan meliputi biaya tetap dan variabel. Biaya tetap meliputi penyusutan alat, sedangkan biaya variabel meliputi biaya pupuk, tenaga kerja, pestisida dan herbisida. Analisis R/C ratio merupakan perbandingan antara penerimaan dan biaya,

2. Hossana (2009), menyatakan dalam penelitian yang berjudul analisis usahatani kopi di Kecamatan Simepang Empat Kabupaten Karo menyimpulkan bahwa faktor-faktor yang mempengaruhi produksi kopi di daerah penelitian adalah pupuk organic, pupuk anorganik, dan curahan tenaga kerja. Faktor produksi yang berpengaruh nyata terhadap produksi secara serempak ada pada umur 2-4 tahun namun secara parsial hanya curahan tenaga kerja yang berpengaruh nyata. 
3. Suseno (2013), menyatakan dalam penelitiannya yang berjudul Analisis usahatani kopi rakyat dan kontribusinya terhadap pendapatan total keluarga studi kasus di Desa Sumberwringin Kabupaten Bondowoso bahwa nilai koefisien regresi variebel jumlah pohon bernilai negatif sebesar 65.579 , jadi setiap penambahan sebesar satu pohon kopi maka pendapatan usahatani kopi akan mengalami penurunan sebsar Rp 65,579.

Terdapat beberapa hipotesis atau dugaan sementara dalam penelitian ini diantaranya yaitu diduga ada perbedaan tingkat produktivitas dan tingkat keuntungan usaha perkebunan kopi di Kecamatan Panti Kabupaten Jember, diduga ada perbedaan tingkat efisiensi penggunaan biaya dalam usaha perkebunan kopi di Kecamatan Panti Kabupaten Jember, dan diduga faktorfaktor yang berpengaruh dalam produksi usahatani kopi di Kecamatan Panti Kabupaten Jember.

\section{METODOLOGI PENELITIAN}

Metode yang digunakan dalam penelitian ini adalah deskriptif dan komparatif. Metode deskriptif digunakan karena dalam

1. Untuk mengetahui produktivitas lahan usahatani kopi digunakan rumus

$$
R / C=\frac{\text { Total Produksi }(\mathrm{kg})}{\text { Luas Lahan }(\mathrm{ha})}
$$

2. Untuk mengetahui keuntungan usaha perkebunan kopi digunakan rumus :

$\pi=\mathrm{TR}-\mathrm{TC}$

$\mathrm{TR}=\mathrm{P} . \mathrm{Q}$

$\mathrm{TC}=\mathrm{TFC}+\mathrm{TVC}$

di mana :

л $=$ keuntungan $(\mathrm{Rp})$

$\mathrm{TR}=$ total penerimaan $(\mathrm{Rp})$

$\mathrm{TC}=$ total biaya $(\mathrm{Rp})$

$\mathrm{Q}=$ total produksi $(\mathrm{Kg})$

$\mathrm{P}=$ harga jual $(\mathrm{Rp})$

$\mathrm{TFC}=$ total biaya tetap $(\mathrm{Rp})$

$\mathrm{TVC}=$ total biaya variabel $(\mathrm{Rp})$

Total keuntungan dapat diproleh dengan cara mengurangi total penerimaan dengan total biaya dalam suatu proses produksi. Adapun total penerimaan diperoleh dari perkalian produksi fisik dengan harga produksi. Menurut penelitian ini akan mendeskripsikan tentang gejala-gejala sosial tertentu atau aspek kehidupan tertentu dari subyek yang diteliti, yaitu petani (Singarimbun dan Efendi, 1995). Penentuan lokasi penelitian yaitu di Desa Panti Kabupaten Jember dilakukan dengan cara sengaja (purposive) dengan pertimbangan bahwa daerah tersebut merupakan kecamatan dengan penghasil kopi terbesar kedua setelah kecamatan Silo.

Sampel di penelitian ini adalah petani kopi robusta dan kopi arabika. teknik pengambilan sampel di penelitian ini yaitu menggunakan teknik Disproportioned Random Sampling, yaitu teknik yang digunakan untuk menentukan jumlah sampel bila populasi berstrata tapi kurang proporsional. Hal ini karena di lokasi penelitian populasi petani kopi robusta dan petani kopi arabika kurang berimbang. Populasi petani kopi robusta sebesar 164 orang, sedangkan jumlah petani kopi arabika sebesar 53 orang. pengambilan sampel dilakukakan di empat desa yaitu Desa Kemiri, Desa Suci, Desa Pakis, Desa Panti Teknik pengumpulan data terbagi menjadi dua yaitu teknik wawancara dan pencatatan. Teknik analisis data digunakan untuk menghitung :

Sumodiningrat, (1989). Total biaya usahatani kopi tersebut diperoleh dari perhitungan pengeluaran-pengeluaran yang digunakan untuk pembayaran atau pembelian bibit, pupuk, tenaga kerja dan obat pembasmi per unit.

3. Efisiensi penggunaan biaya dihitung dengan metode return/cost $(\mathrm{R} / \mathrm{C})$ ratio atau perbandingan antara total penerimaan dengan total biaya

$$
R / C=\frac{\text { Total } \operatorname{Revenue}(T R)}{\text { TotalCost }(T C)}
$$

di mana:

$\mathrm{TR}=\mathrm{Y} . \mathrm{Py}$

$\mathrm{TC}=\mathrm{TFC}+\mathrm{TVC}$

Kriteria :

$\mathrm{R} / \mathrm{C}$ ratio $>1$, berarti usahatani kopi efisien

$\mathrm{R} / \mathrm{C}$ ratio $\leq 1$, berarti usahatani kopi tidak efisien

Dari hasil perhitungan tersebut dapat diperoleh keterangan bahwa semakin besar R/C ratio maka semakin besar pula keuntungan yang diperoleh petani.

4. Untuk mengetahui faKtor-faktor yang berpengaruh terhadap produksi kopi digunakan pendekatan analisis regresi berganda dengan 
asumsi bahwa bentuk hubungan antara variable bebas $(\mathrm{X})$ dengan variable terikat $(\mathrm{Y})$ merupakan fungsi produksi Cobb-Douglas. Hubungan antara variable $\mathrm{X}$ dan $\mathrm{Y}$ tersebut secara matematik dirumuskan sebagai berikut (Sutiarso,2010):

$$
Y=\beta_{0} X_{1 i}^{\beta_{1}} X_{2 i}^{\beta_{2}} \ldots X_{k i}^{\beta_{k}} e^{D+u}
$$

Diduga faktor-faktor yang berpengaruh terhadap produksi usahatani kopi adalah luas lahan, jumlah tenaga kerja, jumlah pupuk, pengalaman, dan varietas berusahatani kopi. Secara sistematik, persamaan taksiran fungsi produksi dengan model regresi adalah

$$
\mathrm{Y}=\beta_{0} X_{1}^{\beta_{1}} X_{2}^{\beta_{2}} X_{3}^{\beta_{3}} X_{4}^{\beta_{4}} X_{5}^{\beta_{5}} X_{6}^{\beta_{6}} X_{7}^{\beta_{7}}
$$

di mana :

$\mathrm{Y}=$ produksi usahatani kopi $(\mathrm{kg})$

$\mathrm{X}_{1}=$ pupuk anorganik $(\mathrm{kg})$

$$
\begin{aligned}
& \mathrm{X}_{2}=\text { pupuk organik }(\mathrm{kg}) \\
& \mathrm{X}_{3}=\text { jumlah populasi (pohon) } \\
& \mathrm{X}_{4}=\text { luas lahan (ha) } \\
& \mathrm{X}_{5}=\text { tenaga kerja }(\mathrm{HOK}) \\
& \mathrm{X}_{6}=\text { pengalaman }(\mathrm{th}) \\
& \mathrm{D}=\text { dummy (varietas) } \\
& \mathrm{D}_{1}=\mathrm{D}_{1} \text { robusta } \\
& \mathrm{D}_{0}=\mathrm{D}_{2} \text { arabika }
\end{aligned}
$$

\section{PEMBAHASAN}

\section{1) Produktivitas dan Keuntungan Usahatani Kopi Robusta dan Arabika}

Guna menguji hipotesis yang pertamsa tentang perbandingan produktivitas dan keuntungan usahatani kopi robusta dan arabika maka digunakan analisis produktivitas dan keuntungan. Tabel 6.2 menunjukkan perbedaan produktivitas antara kopi robusta dan arabika.

Tabel 1. Perbandingan Luas lahan, dan Produktivitas Usahatani Kopi Robusta Dan Arabika di Kecamatan Panti Kabupaten Jember 2016

\begin{tabular}{rccc}
\hline Kopi & Produksi (kg) & Luas lahan (ha) & Produktivitas (kg/ha) \\
\hline Robusta & 1.648 & 1,2 & 1.330 \\
Arabika & 1.194 & 1,5 & 1.150 \\
\hline
\end{tabular}

Sumber: Analisis Data Primer Tahun 2016.

Produktivitas usahatani kopi robusta

\begin{tabular}{|c|c|c|c|c|}
\hline \multirow{2}{*}{ Uraian } & \multicolumn{4}{|c|}{ Petani } \\
\hline & Robusta & $\%$ & Arabika & $\%$ \\
\hline 1. Luas Lahan & 1,2 & & 1,05 & \\
\hline \multicolumn{5}{|l|}{ 2. Biaya Tetap } \\
\hline a. Sewa Lahan & 4.184 .848 & 24,2 & 4.229 .315 & 21,45 \\
\hline b. Penyusutan Alat & 158.851 & 0,9 & 221.610 & 1,123 \\
\hline Total Biaya Tetap & 4.343.699 & 25,16 & 4.450 .935 & 22,57 \\
\hline \multicolumn{5}{|l|}{ 3. Biaya Variabel } \\
\hline a. Biaya Saprodi & & & & \\
\hline Pupuk Organik & 1.838 .556 & 10,65 & 1.979 .187 & 10,03 \\
\hline Pupuk Anorganik & 1.131 .692 & 6,55 & 1.467 .519 & 7,44 \\
\hline Urea & 605.909 & 3,51 & 903.117 & 4,58 \\
\hline Phonska & 239.949 & 1,39 & 289.113 & 1,46 \\
\hline NPK & 72.424 & 0,41 & 83.449 & 0,42 \\
\hline $\mathrm{ZA}$ & 112.197 & 0,65 & 48.080 & 0,24 \\
\hline TSP & 60.404 & 0,34 & 96.465 & 0,48 \\
\hline KCL & 40.808 & 0,23 & 47.272 & 0,23 \\
\hline b. Tenaga Kerja & 8.814 .797 & 51,06 & 10.351 .128 & 52,50 \\
\hline Total Biaya Variabel & 11.673.629 & $\mathbf{7 4 , 8 3}$ & 13.808.037 & 77,42 \\
\hline Total Biaya Produksi & 16.017 .329 & 100 & 18.258 .963 & 100 \\
\hline
\end{tabular}
dan kopi arabika di Kecamatan Panti Kabupaten Jember adalah sebesar 1.330 $\mathrm{kg} / \mathrm{ha}$ untuk kopi robusta dan kopi arabika

sebesar $1.150 \mathrm{~kg} / \mathrm{ha}$. Perbedaan produktivitas tersebut dikarenakan jumlah kadar air yang terdapat dalam kopi arabika lebih kecil dari pada kopi robusta.

Tabel 2. Struktur Biaya Per Hektar Usaha Perkebunan Kopi Robusta dan Arabika di Kecamatan Panti Tahun 2016

Sumber : Analisis Data Primer, 2016 
Berdasarkan tabel 6.5, struktur biaya pada usahatani kopi robusta dan kopi arabika di Kecamatan Panti yaitu biaya total adalah pertambahan biaya variabel dan biaya biaya total. Total biaya variabel kopi robusta sebesar Rp 11.673.629 yaitu $74,83 \%$, total biaya variabel petani kopi arabika sebesar $\mathrm{Rp}$ 13.808.037 yaitu 77,42\%. Sedangkan biaya tenaga kerja petani kopi robusta sebesar Rp 8.814.797 yaitu $51,06 \%$, biaya tenaga kerja petani kopi arabika sebesar Rp 10.351.128 yaitu $52,50 \%$. Biaya pupuk organik petani kopi robusta sebesar Rp 1.838.556 yaitu 10,65\%, biaya pupuk organik petani kopi arabika sebesar Rp 1.979.187 yaitu 10,03\%. Sedangkan biaya pupuk anorganik petani kopi robusta terdiri dari urea, phonsa, npk, za, tsp, kcl menunjukkan bahwa pupuk urea penggunaan tertinggi oleh petani kopi robusta sebesar Rp 605.909 yaitu 3,51\%, sedangkan untuk petani kopi arabika adalah pupuk urea juga sebesar Rp 903.117 yaitu 4,58\%. 24,21\%, biaya sewa lahan petani kopi arabika sebesar 4.229.315 yaitu 21,45\%.

Unsur biaya tetap terdiri dari sewa lahan dan penyusutan alat-alat produksi, dimana total biaya tetap petani kopi robusta sebesar Rp 4.343.699 yaitu $25,16 \%$, sedangkan petani kopi arabika sebesar Rp 4.450 .935 yaitu $22,57 \%$. Sewa lahan petani kopi robusta sebesar Rp 4.184.848 yaitu $24,20 \%$, sedangkan sewa lahan petani kopi arabika sebesar Rp 4.229.315 yaitu $21,45 \%$. Semakin besar biaya sewa lahan kopi ditentukan oleh seberapa besar produksi kopi robusta maupun arabika per hektar.

Gustiana (2004) menuturkan bahwa dalam pendapatan usahatani terdapat dua macam pengertian pedapatan yaitu pendapatan kotor dan pendapatan bersih. Pendapatan kotor yaitu pendapatan yang diperoleh oleh petani dalam usahatani selama satu tahun yang dapat diperhitungkan dan hasil produksi yang dinilai dalam rupiah berdasarkan harga persatuan berat pada saat pemungutan hasil dan Pendapatan bersih yaitu pendapatan yang diperoleh petani dalam satu tahun dikurangi dengan biaya produksi dalam proses produksi.

Biaya usahatani adalah semua pengeluaran yang dipergunakan dalam usahatani. Biaya usahatani dibedakan menjadi dua yaitu yaitu biaya tetap dan biaya tidak tetap/biaya variabel (Soekartawi, 1995). Biaya tetap adalah biaya biaya yang tidak terpengaruh oleh besar kecilnya produksi yang dihasilkan. Sedangkan biaya variabel adalah biaya yang dikeluarkan dalam proses produksi yang besarnya berubah-ubah tergantung dari besar kecilnya produksi. Penerimaan usahatani adalah hasil perkalian dari jumlah produksi dengan harga jual produksi.

Tabel 3. Rata-Rata Keuntungan Per hektar Usaha Perkebunan Kopi Robusta dan Arabika di Kecamatan Panti 2016

\begin{tabular}{cccrrr}
\hline \multirow{2}{*}{ No } & \multirow{2}{*}{ Uraian } & \multirow{2}{*}{ Satuan } & \multicolumn{2}{c}{ Jenis Kopi } & \multirow{2}{*}{ Rata-rata } \\
\cline { 4 - 5 } & & ha & \multicolumn{1}{c}{ Robusta } & Arabika & 1,2 \\
2 & Puas lahan & $\mathrm{hg} / \mathrm{ha}$ & 1.330 & 1,05 & 125 \\
3 & Harga Jual & $\mathrm{Rp} / \mathrm{kg}$ & 22.000 & 1.150 & 1240 \\
4 & Penerimaan & $\mathrm{Rp}$ & 29.293 .333 & 33.541 .000 & 25.500 \\
5 & Biaya produksi & $\mathrm{Rp}$ & 16.017 .329 & 18.258 .963 & 31.417 .201 \\
6 & Keuntungan & $\mathrm{Rp}$ & 13.276 .003 & 15.282 .105 & 17.138 .146 \\
\hline
\end{tabular}

Sumber :Analisis Data Primer 2016

Berdasarkan pada tabel 6.5 dapat diketahui bahwa usahatani kopi robusta dan kopi arabika di Kecamatan Panti Kabupaten Jember tahun 2016 menguntungkan secara ekonomi karena rata-rata biaya total yang dikeluarkan petani kopi robusta sebesar $\mathrm{Rp}$ 16.017.329, rata-rata penerimaan yang diperoleh oleh petani kopi robusta sebesar Rp 29.293.333. Keuntungan berdasarkan hasil pengurangan dari penerimaan dengan total biaya. Maka keuntungan petani kopi robusta sebesar Rp 13.276.003. Rata-rata total yang dikeluarkan oleh petani kopi arabika sebesar Rp 18.258.963, rata-rata penerimaan yang diperoleh oleh petani kopi arabika sebesar Rp 33.541.069, keuntungan berdasarkan hasil 
pengurangan dari penerimaan dengan total biaya. Maka keuntungan petani kopi arabika sebesar Rp 15.282.105.

\section{2) Efisiensi Biaya Usaha Perkebunan Kopi robusta dan Kopi Robusta}

Efisiensi biaya merupakan upaya untuk mencapai tujuan dengan menggunakan sumbersumber seminimal mungkin. Efisiensi dalam praktek yang selalu dikaitkan dengan perbandingan biaya (korbanan) dengan output atau hasil (Mubyarto, 1996). Hasil efisiensi biaya petani kopi yang didapat di Kecamatan Panti Kabupaten Jember ini didasari dengan pembagian hasil dari pendapatan usahatani kopi robusta dan arabika dengan penggunaan biaya tetap.

Tabel 4. Efisiensi Biaya Usaha Perkebunan Kopi Robusta dan Arabika di Kecamatan Panti Kabupaten Jember 2016

\begin{tabular}{llcc}
\hline \multirow{2}{*}{ No } & \multicolumn{1}{c}{ Keterangan } & Robusta & Jumlah \\
\cline { 2 - 3 } & \multicolumn{2}{c}{ Arabika } \\
\hline 1 & Penerimaan & 29.293 .333 & 33.541 .069 \\
2 & Biaya Produksi & 16.173 .329 & 18.258 .963 \\
3 & Efisiensi Biaya & 1.86 & 1.89 \\
4 & Pengujian Kriteria & Efisien & Efisien \\
\hline
\end{tabular}

Sumber : Analisis Data Primer 2016

Dari Tabel 6.8 menunjukkan bahwa efisiensi biaya pada usahatani kopi robusta dan arabika di Kecamatan Panti tahun 2016 tidak jauh berbeda dalam penerapan efisiensi biaya. Total penerimaan yang diperoleh oleh petani kopi robusta adalah sebesar Rp 29.293.333 dan petani kopi arabika sebesar Rp 33.541.069. Sedangkan dalam total penggunaan biaya yang dikeluarkan oleh petani kopi robusta sebesar Rp 16.173.329 dan petani kopi arabika sebesar Rp 18.258.963. Total pengeluaran biaya yang dikeluarkan oleh masing-masing petani tidak jauh berbeda karena penggunaan input sarana produksi relative sama dan hanya berbeda dalam banyaknya hari yang digunakan. Efisiensi biaya produksi yang dikeluarkan oleh petani kopi robusta sebesar 1.86 dan kopi arabika sebesar 1.89.

\section{Faktor - Faktor Yang Mempengaruhi Produksi Kopi}

Faktor-faktor yang mempengaruhi produksi petani kopi robusta dan arabika di kecamtan Panti kabuaten Jember dianalisis menggunakan metode analisis regresi linear berganda. Variabel yang digunakan dalam persamaan model adalah produksi (Y) yang diperngaruhi oleh lima variable indipenden yaitu $\left(\mathrm{X}_{1}\right)$ pupuk anorganik, $\left(\mathrm{X}_{2}\right)$ pupuk organik, $\left(\mathrm{X}_{3}\right)$ populasi kopi, $\left(\mathrm{X}_{4}\right)$ Luas lahan, $\left(\mathrm{X}_{5}\right)$ tenaga kerja,(x6) pegalaman $\left(\mathrm{D}_{1}\right)$ variable dummy varietas. Analisis regresi linear berganda ini ditujukan untuk mengetahui pengaruh variable indipenden terhadap variable dependen. Variable indipenden memiliki sifat sebagai variable penyebab, sedangkan variable dependen memiliki sifat sebagai variable akibat. Sebelum melakukan pengujian regresi linear berganda, perlu dilakukan terlebih dahulu uji asumsi klasik terhadap data yang tujuannya adalah menghindari bias dalam analisis data. Pengujian asumsi klasik meliputi uji autokorelasi, multikoleniaritas, heterokedastis, dan normalitas.

\subsection{Uji Autokorelasi}

Tabel 5. Nilai Durbin Witson Faktor-Faktor yang mempengaruhi produksi kopi Robusta dan Arabika

\begin{tabular}{|c|c|c|c|c|c|c|c|c|}
\hline \multirow[b]{2}{*}{$\mathrm{R}$} & \multirow{2}{*}{$\begin{array}{c}\mathrm{R} \\
\text { Square }\end{array}$} & \multirow{2}{*}{$\begin{array}{l}\text { Adjusted R } \\
\text { Square }\end{array}$} & \multirow{2}{*}{$\begin{array}{l}\text { Std. Error of the } \\
\text { Estimate }\end{array}$} & \multicolumn{4}{|c|}{ Change Statistics } & \multirow{2}{*}{$\begin{array}{l}\text { Durbin- } \\
\text { Watson }\end{array}$} \\
\hline & & & & $\begin{array}{l}\text { R Square } \\
\text { Change }\end{array}$ & $\begin{array}{c}\mathrm{F} \\
\text { Change }\end{array}$ & df1 df2 & $\begin{array}{c}\text { Sig. F } \\
\text { Change }\end{array}$ & \\
\hline $.966^{\mathrm{a}}$ & .934 & .926 & .15715 & .934 & 116.848 & 758 & .000 & 2.509 \\
\hline
\end{tabular}

Sumber: Analisis Data Primer 2016. 
Dalam penghitungan uji autokorelasi yang menggunakan aplikasi spss 10.16 menunjukkan bahwa tabel Durbin Watson menunjukkan hasil 2,509. Artinya dw staststik tidak menghasilkan keseimpulan yang pasti Hal ini menunjukkan bahwa terjadi autokorelasi dalam data tersebut.

\subsection{Uji Multikoleniaritas}

Tabel 6. Output Nilai Varians Inflation Faktor Spss 16.10 Usaha Perkebunan Kopi Robusta dan Arabika di Kecamatan Panti Kabupaten Jember Tahun 2016

\begin{tabular}{lcc}
\hline \multirow{2}{*}{ Variable Independen } & \multicolumn{2}{c}{ Korelasi } \\
\cline { 2 - 3 } & Tolerance & VIF \\
\hline Pupuk anorganik & 0,712 & 1,405 \\
Pupuk organik & 0,178 & 5,624 \\
Populasi & 0,217 & 4,616 \\
Luas lahan & 0,103 & 9,674 \\
Tenaga kerja & 0,163 & 4,125 \\
Pengalaman & 0,903 & 1,108 \\
Varietas & 0,671 & 1,491 \\
\hline
\end{tabular}

Sumber: Analisis Data Primer 2016.

Tabel 6.10 bahwa dari tujuh variable yang diujikan menunjukkan bahwa tidak terjadi gejala multikoleniaritas. Berarti dapat

diamabil kesimpulan bahwa tidak terjadi gejala multikoleniaritas dalam data tersebut.

\subsection{Uji Heterokedastis}

Tabel 7. Uji Glesjer Spss 16.10 Usaha Perkebunan Kopi Robusta dan Arabika di Kecamatan Panti Kabupaten Jember 2016

\begin{tabular}{lcc}
\hline \multicolumn{1}{c}{ Variabel } & t-hitung & Signifikansi \\
\hline Konstanta & 0.150 & .882 \\
Pupuk anorganik & -0.010 & .992 \\
Pupuk organik & -1.224 & .226 \\
Populasi tanaman & 1.537 & .130 \\
Luas lahan & 0.415 & .425 \\
Tenaga kerja & $-0,286$ & .408 \\
Pengalaman & $-0,755$ & .382 \\
Dummy varietas & $-0,024$ & .981 \\
\hline
\end{tabular}

Sumber : Analisis Data Primer 2016.

Pada tabel 7 menunjukkan bahwa nilai signifikansi lebih dari 0,05 . Dapat

disimpulkan bahwa tidak terjadi gejala heterokedastisitas pada model regresi.

\subsection{Uji Normalitas}

Tabel 8. Nilai Kolmogorov-Smirnov Faktor-Faktor yang mempengaruhi produksi kopi Robusta dan Arabika

\begin{tabular}{llr}
\hline N & & 66 \\
Normal Parameters $^{\mathrm{a}}$ & Mean & 0.0000000 \\
& Std. Deviation & 0.14844971 \\
Kolmogorov-Smirnov Z & & 0.955 \\
Asymp. Sig. (2-tailed) & & 0.321 \\
\hline
\end{tabular}

Sumber : Analisis Data Primer 2016.

Keterangan dari tabel 6.13 dapat ditarik kesimpulan bahwa nilai signifikansi lebih dari
0,05 , hal tersebut berarti data yang digunakan telah terdistribusi normal.

Tabel 9. Faktor-Faktor Yang Mempengaruhi Produksi Usaha Perkebunan Kopi di Kecamatan Panti Kabupaten Jember Tahun 2016 
Jurnal Agribest Vol 02 No 01, Maret 2018: 14-23

\begin{tabular}{lcccc}
\hline \multicolumn{1}{c}{ Variabel } & Parameter & Koefisien regresi & t & Sig \\
\hline Konstanta & $\beta_{0}$ & 6,757 & $7,434^{* * *}$ & 0,000 \\
Pupuk anorganik $\left(\mathrm{X}_{1}\right)$ & $\beta_{1}$ & 0,035 & $0,749^{\mathrm{ns}}$ & 0,457 \\
Pupuk organik $\left(\mathrm{X}_{2}\right)$ & $\beta_{2}$ & 0,106 & $1,310^{\mathrm{ns}}$ & 0,195 \\
Populasi $\left(\mathrm{X}_{3}\right)$ & $\beta_{3}$ & $-0,115$ & $-1,241^{\mathrm{ns}}$ & 0,220 \\
Luas lahan $\left(\mathrm{X}_{4}\right)$ & $\beta_{4}$ & 0,919 & $8,393^{* * *}$ & 0,000 \\
Tenaga kerja $\left(\mathrm{X}_{5}\right)$ & $\beta_{5}$ & 0,014 & $0,155^{\mathrm{ns}}$ & 0,878 \\
Pengalaman $\left(\mathrm{X}_{6}\right)$ & $\beta_{6}$ & 0,014 & $0,217^{\mathrm{ns}}$ & 0,829 \\
Varietas $(\mathrm{D})$ & $\mathrm{B}_{7}$ & 0,149 & $3,146^{* *}$ & 0,003 \\
\hline Std. Error Estimasi & & 15715 & & \\
R Square & $\mathrm{R}^{2}$ & 0.934 & 0,926 & \\
Adjusted R Square & $-\mathrm{R}^{2}$ & $116.848^{* * *}$ & & \\
F-Hitung & & 66 & \\
N & & & \\
\hline
\end{tabular}

Keterangan :, **,***.95\%,99\%, ns: tidak signifikan

Sumber : Analisis Data Primer 2016

Persamaan garis regresi fungsi produksi usahatani kopi robusta dan kopi arabika adalah

$\operatorname{Ln} Y=6,757+0,035 \ln X_{1}+0,106 \ln X_{2}+$ $-0,115 \ln X_{3}+0,919 \ln X_{4}+0,014 \ln X_{5}+$ $0,014 \ln \mathrm{X}_{6}+0,149 \ln \mathrm{D}$

Pada kopi arabika $\mathrm{D}=0$, sehingga formulasi persamaan regresinya adalah:

$\mathrm{Ln} \mathrm{Y}=6,757+0,035 \ln \mathrm{X}_{1}+0,106 \ln \mathrm{X}_{2}+$ $-0,115 \ln \mathrm{X}_{3}+0,919 \ln \mathrm{X}_{4}+0,014 \ln \mathrm{X}_{5}+$ $0,014 \ln \mathrm{X}_{6}+(0,149 \mathrm{x} 0)$

Pada kopi robusta $\mathrm{D}=1$, maka persamaan regresinya adalah:

$\operatorname{Ln} Y=6,757+0,035 \ln X_{1}+0,106 \ln X_{2}+$ $-0,115 \ln X_{3}+0,919 \ln X_{4}+0,014 \ln X_{5}+$ $0,014 \ln \mathrm{X}_{6}+(0,149 \times 1) \operatorname{Ln} \mathrm{Y}=6,906+$ $0,035 \ln X_{1}+0,106 \ln X_{2}+-0,115 \ln X_{3}+$ $0,919 \ln X_{4}+0,014 \ln X_{5}+0,014 \ln X_{6}$ Secara matematik dapat diformulasikan dengan fungsi produksi cobb-douglas sebagai berikut:

Pada kopi arabika

$\mathrm{Y}=860,05 \mathrm{X}_{1}{ }^{0,035} \mathrm{X}_{2}{ }^{0,106} \mathrm{X}_{3}{ }^{-0,115} \mathrm{X}_{4}{ }^{0,919}$ $\mathrm{X}_{5}{ }^{0,014} \mathrm{X}_{6}{ }^{0,014}$

Pada kopi robusta

$\mathrm{Y}=805,37 \mathrm{X}_{1}{ }^{0,035} \mathrm{X}_{2}{ }^{0,106} \mathrm{X}_{3}{ }^{-0,115} \mathrm{X}_{4}{ }^{0,919}$ $\mathrm{X}_{5}{ }^{0,014} \mathrm{X}_{6}{ }^{0,014}$

Pada Tabel 6.14 menunjukkan bahwa tingkat produksi dalam usahatani kopi robusta dan arabika diasumsikan dipengaruhi oleh faktor : (1) pupuk anorganik; (2) pupuk organik; (3) populasi pohon; (4) luas lahan; (5) tenaga kerja; (6) pengalaman; (7) dummy varietas. Pengaruh antara pupuk anorganik, pupuk organik, jumlah populasi, luas lahan, tenaga kerja, pengalaman, dan dummy varietas berpengaruh secara signifikan terhadap produksi usahatani kopi robusta dan arabika. Hal ini data dilihat dari nilai Fhitung (116.848) dengan taraf uji $1 \%$.

Dilihat dari nilai koefisien determinasi $\left(\mathrm{R}^{2}\right)$ yaitu sebesar 0,934 menunjukkan bahwa variabel bebas dimaksudkan ke dalam model dapat menjelaskan variasi variabel dependen (produksi) secara baik sekitar 93,4\%. Hanya $6,6 \%$ yang dijelaskan oleh faktor lain yang tidak masuk ke dalam model, di antaranya umur petani dan tingkat pendidikan petani.

Apabila dilihat dari nilai koefisien regeresi parsial yang menggunakan fullmodel, maka faktor produksi pupuk anorganik, pupuk organik, populasi, tenaga kerja, dan pengalaman tidak berpengaruh nyata terhadap produksi kopi robusta dan arabika, sedangkan faktor produksi yang berpengaruh nyata adalah luas lahan dan dummy varietas.

1. Pupuk Anorganik $\left(\mathrm{X}_{1}\right)$

Faktor penggunaan pupuk anorganik oleh petani kopi rabosta dan arabika secara statistic tidak signifikan pada taraf uji $1 \%$ dan pengaruh positif terhadap produksi usahatani kopi robusta dan kopi arabika. Artinya jika jumlah pupuk organik bertambah sebesar $1 \%$ maka akan meningkatkan produksi kopi robusta dan kopi arabika sebesar 0,035\%. 
Rata-rata penggunaan pupuk anorganik di daerah penelitian $668.18 \mathrm{~kg}$. jumlah pupuk tersebut tergolong kecil dalam pengusahaan usahatani kopi. Penggunaan pupuk anorganik yang kecil dikarenakan pupuk anorganik di daerah peneletian hanya digunakan untuk rangsangan agar pupuk organik yang di berikan pada tanaman kopi mudah terserap oleh tanaman kopi di daerah penelitian.

2. Pupuk Organik $\left(\mathrm{X}_{2}\right)$

Faktor penggunaan pupuk organik oleh petani kopi robusta dan kopi arabika di daerah penelitian berpengaruh positif, tetapi secara statistic signifikan. Artinya, penggunaan pupuk organik yang digunakan berpengaruh secara nyata terhadap produksi usahatani kopi robusta dan kopi arabika. Secara ekonomik dapat diartikan bahwa setia penambahan jumlah pupuk sebesar $1 \%$ maka produksi yang diperoleh petani akan meningkat rata-rata sekitar $0,106 \%$. Signifikannya faktor penggunaan pupuk organik dikarenakan bahwa pupuk kandang berfungsi untuk mengikat air tanah yang lebih besar sehingga pupuk yang terlarut masih tersedia dalam tanah, selain itu pupuk kandang juga meningkatkan daya agresi tanah, pori-pori tanah dan air tanah sehingga hara menjadi trsedia bagi tanaman dan dengan demikian akan memicu pertumbuhan dan produksi tanaman kopi robusta dan kopi arabika. Rata-rata penggunaan pupuk organik di daerah penelitian sekitar $2.115 \mathrm{~kg}$ per petani.

3. Jumlah Populasi Tanaman $\left(\mathrm{X}_{3}\right)$

Faktor populasi tanaman oleh petani kopi robusta dan arabika di daerah penelitian berpengaruh negatif. Tetapi secara statistik berpengaruh secara signifikan. Artinya, populasi tanaman tidak berpengaruh nyata terhadap produksi usahatani kopi robusta dan kopi arabika. Jadi jumlah jumlah populasi tanaman kopi robust dan kopi arabika bertambah $1 \%$, maka akan mengalami penurunan produksi kopi robusta dan kopi arabika sebesar $0,015 \%$ dengan taraf uji $10 \%$. Rata-rata populasi pohon kopi robusta dan arabika di daerah penelitian 1728 pohon untuk kopi robusta dan koi arabika sebesar 2414 pohon.

\section{Luas Lahan $\left(\mathrm{X}_{4}\right)$}

Faktor luas lahan oleh petani kopi robusta dan kopi arabika berpengaruh positif dan secara statistic berpengaruh secara signifikan. Artinya luas lahan berpengaruh nyata terhadap produksi kopi robusta dan kopi arabika bila luas lahan bertambah 1\% maka akan meningkatkan produksi kopi robusta dan kopi arabika sebesar 0,919\%. Dengan taraf uji 99\%. Rata-rata luas lahan kopi di Kecamtan Panti sebesar 1.14 ha baik kopi robusta dan arabika.

\section{Tenaga $\operatorname{Kerja}\left(\mathrm{X}_{5}\right)$}

Faktor penggunaan tenaga kerja berpengaruh positif terhadap produksi akan tetapi secara statistic tidak berpengaruh secara signifikan. Artinya, semakin besar tenaga kerja yang digunakan petani, maka semakin tinggi pula produksi yang dihasilkan. Bila petani menambah tenaga kerja sebesar $1 \%$ maka akan meningkatkan produksi kopi robusta dan kopi arabika sebesar 0,014\% dengan taraf uji 99\%. Penambahan tenaga kerja akan dapat meningkatkan produksi kopi arabika dengan berkontribusi pada kegiatan pemupukan dan panen buah kopi yang membutuhkan kopi yang tenaga banyak (Syahruni,2014). Ratarata penggunaan tenaga kerja di Kecamatan Panti Kabupaten Jember sebesar 292 orang.baik robusta maupun arabika.

\section{Pengalaman $\left(\mathrm{X}_{6}\right)$}

Faktor pengalaman mempunyai koefisien regresi yang bernilai positif antara variable independen pengalaman dengan produksi kopi robusta maupun arabika di Kecamatan Panti Kabupaten Jember. Nilai koefisien regresi yang diperoleh 0,014 memiliki arti bahwa setiap penambahan pengalaman 1 tahun maka dapat menambah produksi kopi robusta maupun arabika sebesar 0,014 Kg dengan asumsi variable lain tetap. Hasil uji statistic menunjukkan bahwa faktor pengalaman berpengaruh tidak nyata terhadap produksi kopi robusta maupun arabika di Kecamatan Panti Kabupaten Jember dengan taraf kepercayaan 95\%.. Rata-rata pengalaman berusahatani kopi di Kecamatan Panti Kabupaten Jember adalah 
17,5 tahun. Hal tersebut tergolong tinggi dalam berusahatani kopi.

7. Dummy Varietas $\left(\mathrm{D}_{1}\right)$

Faktor dummy bibit mempunyai koefisien regresi yang bernilai positif artinya terhadap pengaruh positif antara variable bibit dengan produksi kopi di Kecamatan Panti Kabupaten Jember. Nilai koefisien regresi yang diperoleh adalah sebesar 0,149 menunjukkan bahwa produksi petani kopi robusta lebih tinggi 0,149 dibandingkan dengan kopi arabika. Hasil uji statistic menunjukkan bahwa faktor dummy varietas tidak berpengaruh nyata terhadap produksi kopi di Kecamatan Panti Kabupaten Jember dengan taraf signifikansi Dengan perbandingan bibit yang sama (33-33).

\section{KESIMPULAN}

Dalam penelitian ini dapat ditarik beberapa kesimpulan yaitu ada perbedaan tingkat produktivitas antara kopi robusta dan kopi arabika di Kecamatan Panti Kabupaten Jember yang nyata secara statistik pada taraf kepercayaan 95\%.dengan Produktivitas kopi robusta sebesar $1.330 \mathrm{~kg} / \mathrm{ha}$ dan kopi arabika sebesar $1.150 \mathrm{~kg} / \mathrm{ha}$. Terdapat pebedaan keuntungan per hektar kopi antara kopi robusta dan arabika di Kecamatan Panti Kabupaten Jember yang nyata secara statistik pada taraf kepercayaan 95\%. Keuntungan kopi robusta sebesar Rp. 13.276.003 per hektar dan kopi arabika sebesar Rp. 15.282.105 per hektar. Ada perbedaan efisiensi penggunaan biaya antara kopi robusta dan arabika di Kecamatan Panti Kabupaten Jember yang nyata secara statistik pada taraf kepercayaan 95\%. Efisiensi penggunaan biaya dicerminkan oleh nilai $\mathrm{R} / \mathrm{C}$ ratio. $\mathrm{R} / \mathrm{C}$ ratio kopi robusta sebesar 1,86 $\mathrm{R} / \mathrm{C}$ arabika sebesar 1,89. Faktor-faktor produksi yang berpengaruh secara nyata adalah luas lahan dan dummy varietas, sedangkan faktor-faktor produksi yang berpengaruh secara tidak nyata adalah pupuk anorganik, pupuk organik, populasi, tenaga kerja, dan pengalaman.

\section{DAFTAR PUSTAKA}

Hossana. A, 2009, Analisi Usahatani Kopi di Kecamatan Simpang Empat Kabupaten Karo. Skripsi. Fakultas pertanian Universitas Sumatera Utara. Medan.

Nazir, M. 2009. Metode Penelitian. Ghalia Indonesia. Jakarta.

Singarimbun dan Efendi.1995. Metode Penelitian Survei. LP3ES. Jakarta.

Suseno, A. 2013. Analisis Usahatani Kopi Rakyat dan Kontribusinya Terhadap Pendapatan Total keluarga di Kecamatan Sumberwringin Kabupaten Bondowoso. Skripsi. Universitas Negeri Jember. Jember.

Sutiarso, Edy. 2010. Analisis Regresi Sederhana, Jurusan Sosial Ekonomi Pertanian. Fakutas Pertanian. Universitas Muhammadiyah Jember. Jember.

Thamrin, Syahruni. 2014. Faktor-Faktor yang Mempengaruhi Produksi Usahatani Kopi Arabika di Kabupaten Enrekang Sulawesi Selatan. Skripsi. Politeknik Pertanian Pangkep. Sulawesi Selatan. 